\title{
INTENÇÃO EMPREENDEDORA: EVIDÊNCIAS EMPÍRICAS DOS SEUS PRINCIPAIS DETERMINANTES
}

Deranor Gomes De Oliveira ${ }^{1}$

${ }^{1}$ Universidade Federal do Vale do São Francisco 


\section{INTENÇÃO EMPREENDEDORA: EVIDÊNCIAS EMPÍRICAS DOS SEUS PRINCIPAIS DETERMINANTES}

\section{Resumo}

Este estudo tem por objetivo testar um modelo teórico, numa perspectiva longitudinal, capaz de explicar o impacto de variáveis que antecedem a formação da intenção empreendedora. $\mathrm{O}$ enquadramento teórico teve como base os estudos teóricos e empíricos de Ajzen (1991), Bandura (1986) e Shapero e Sokol (1982), que sugerem a intenção, uma função da conveniência e da viabilidade percebida e da pressão social. Este trabalho adotou uma abordagem quantitativa, de natureza descritiva, ao descrever características de determinada população - intenção empreendedora e explicativa - estabelecer relações entre variáveis, usando métodos padronizados de coleta e análise de dados. Os dados foram tratados estatisticamente, recorrendo-se à análise de modelos de equações estruturais. As percepções da autoeficácia e da atratividade foram as variáveis que mais explicaram a intenção empreendedora. Os resultados poderão servir de base para estabelecer uma série de ponderações sobre a função mais eficaz da educação em promover e desenvolver o empreendedorismo.

Palavras-chave: Intenção empreendedora. Autoeficácia empreendedora. Atratividade percebida. Educação para o empreendedorismo. 


\section{Introdução}

Há tempos que a literatura científica na área de empreendedorismo vem sugerindo a existência de relações importantes entre a educação para o empreendedorismo e a atividade empresarial, seja na criação de negócio ou no desempenho organizacional. A educação e a experiência laboral foram consideradas fatores relevantes que desempenham um papel crucial na identificação de oportunidades empresariais (Ucbasaran, Westhead e Wright, 2008). No entanto, Raposo e Paço (2011) alertam que os resultados dos programas dessa modalidade de ensino não são imediatos; por essa razão, são susceptíveis de serem encobertos por outras variáveis individuais ou ambientais mais próximas da ação de empreender.

O surgimento de negócios comumente é considerado um indicador-chave do empreendedorismo. Para Baron e Shane (2007) que definem o empreendedorismo como a identificação, avaliação e exploração de oportunidades para criar bens e serviços futuros, isso ocorre porque as pessoas são motivadas a identificarem e explorarem oportunidades de negócios. O ponto de partida de um comportamento é a formação de uma intenção (Ajzen, 1991). Essa é uma visão enraizada na teoria que a intenção é resultante de fatores endógenos e exógenos: entre eles, a percepção da conveniência e da viabilidade e a pressão das normas sociais são os melhores preditores da intenção (Shapero e Sokol, 1982; Bandura, 1986 e Ajzen, 1991).

O objetivo deste estudo foi testar um conjunto de hipóteses de um modelo teórico, numa perspectiva longitudinal, em que as percepções da autoeficácia empreendedora (viabilidade), da atratividade (conveniência) e da educação para o empreendedorismo (normas sociais) em nível individual, para além das relações entre si, impactam diretamente a intenção empreendedora dos estudantes universitários brasileiros. Os resultados deste trabalho poderão ajudar a determinar, por meio de uma análise baseada em dados empíricos, quais dessas variáveis em estudo são preponderantes na determinação da intenção empreendedora.

$\mathrm{O}$ artigo encontra-se estruturado em cinco seções, contadas a partir desta introdução. Na seção 2, o referencial teórico é organizado em dois tópicos - o primeiro descreve modelos teóricos, comumente, utilizados para explicar a relação entre antecedentes e a intenção empreendedora e o segundo centrado no modelo teórico adotado para as análises empíricas, as variáveis em estudos e o conjunto de hipóteses; na seção 3, o método é estruturado em dois tópicos - Amostra de interesse (participantes) e o tratamento estatístico dos dados; na seção 4, são apresentadas a análise e a discussão dos resultados, em dois horizontes temporais: (a) antes do curso de empreendedorismo (T1) e (b) Pós-curso de empreendedorismo (T2); por fim, na seção 5, são feitas as considerações finais.

\section{Referencial Teórico}

\subsection{Modelos teóricos utilizados para explicar as intenções empreendedoras.}

As formas convencionais de visualizar os aspectos sociais do empreendedorismo foram consideradas insatisfatórias por Shapero e Sokol (1982), e Krueger, Reilly e Carsrud (2000) argumentaram que, empiricamente, as variáveis situacionais, por exemplo, situação empregatícia, ou as características demográficas, ou ainda, os traços de personalidade são considerados preditores pobres. Prever as ações empreendedoras por fatores pessoais ou apenas situacionais de modelagem, geralmente, resultou em pouco poder explicativo e, até
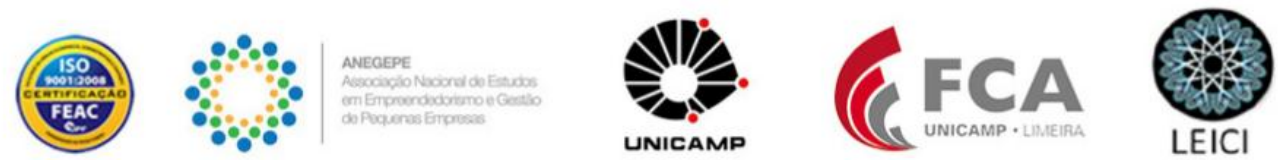
mesmo, menor validade preditiva. Ajzen (1991) argumenta que a intenção representa um extraordinário preditor do comportamento humano e, por sua vez, teorias existentes, como a Teoria do Evento Empresarial (Shapero \& Sokol, 1982), a Teoria de Aprendizagem Social e da Autoeficácia de Bandura (1986) e a Teoria do Comportamento Planejado de Ajzen (1991), com intuito de preencher essa lacuna existente no campo, sugerem que as intenções sejam, em grande parte, uma função das percepções de conveniência, percepções de viabilidade e da pressão social exercida.

A Teoria do Evento Empresarial de Shapero e Sokol (1982) considera a criação de um novo empreendimento como resultado da interação de agrupamentos de variáveis sociais, tais como os grupos étnicos e o ambiente social e cultural - exercendo uma influência na percepção do sistema de valores do indivíduo. Para Krueger et al. (2000) o evento empresarial é denotado pela tomada de iniciativa, consolidação de recursos, gestão, autonomia relativa e assunção de riscos. Influências exógenas, por si sós, não iriam determinar diretamente o comportamento de criação de empresa; as respostas das pessoas a um evento externo iriam depender de suas percepções sobre as alternativas disponíveis, o que para Shapero e Sokol (1982) e Krueger et al. (2000).), seria o resultado da análise (consciente ou inconsciente) realizada pela pessoa sobre a conveniência, a propensão para agir e a viabilidade das alternativas situacionais. Essas influências exógenas operariam por meio de percepções da conveniência e da viabilidade variando de pessoa-situação.

Na Teoria Social Cognitiva de Bandura (1986), a autoeficácia é definida como uma crença, ou percepção, ou expectativa das pessoas. Nas palavras do autor (pp. 391), "um julgamento das próprias capacidades de executar cursos de ação exigidos para se atingir certo grau de desempenho". As mudanças comportamentais são possíveis apenas na medida em que o indivíduo tiver um forte nível de autoeficácia, o que nas palavras de Medeiros et al. (2000) são as convicções pessoais de que tem capacidade de executar os comportamentos exigidos para atingir os resultados pretendidos, e sem desistir no percurso. É uma variável psicológica distinta e que vai além dos próprios conhecimentos específicos, das habilidades ou das experiências de realizações anteriores, exercendo uma influência sobre o comportamento absolutamente relevante (Bandura, 1986; Medeiros et al. 2000). A teoria de Bandura tem sido considerada uma das poucas teorias psicológicas que, desenvolvida nas últimas décadas do século passado, continua a influir, consideravelmente, os estudos na área de empreendedorismo (Zahao et al., 2005).

A Teoria do Comportamento Planejado de Ajzen (1991) emergiu como um dos mais populares, completos e influentes quadros conceituais para os estudos direcionados para a ação humana. A intenção foi definida como uma função de três antecedentes: i) uma avaliação favorável ou desfavorável do comportamento (atitude); ii) a pressão social percebida para executar ou não executar o comportamento (norma subjetiva); iii) a facilidade ou dificuldade percebida de executar o comportamento (controle comportamental percebido). $\mathrm{O}$ comportamento de iniciar um novo empreendimento é intencional e planejado, e a teoria de Ajzen é adequada para compreendê-lo. A teoria do comportamento planejado foi aplicada para estudar as intenções do autoemprego (por exemplo, Krueger, Reilly e Carsrud, 2000; Souitaris, Zerbinati e Al-Lavigne, 2007). É, sem dúvida alguma, uma das teorias de previsão comportamental mais estudada, tendo sido extensamente validada.
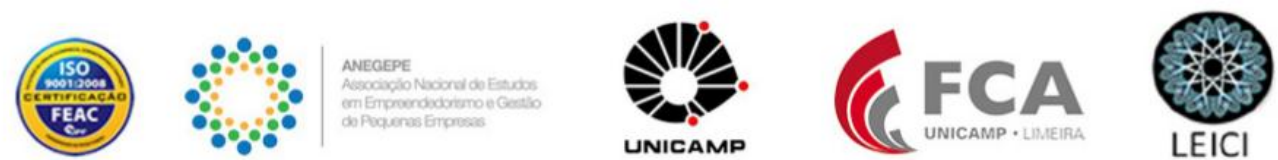
Essas teorias, na perspectiva de Krueger et al. (2000), foram classificadas como poderosas em prever as intenções empreendedoras, no entanto, são modelos dependentes, principalmente, de três variáveis: a percepção da conveniência, a percepção da viabilidade e as normas sociais; todas pensadas para influenciar diretamente as intenções empreendedoras. Peterman e Kennedy (2003) chamaram a atenção para a relevância de um número de variáveis que poderiam ser adicionadas a esses modelos teóricos. Nessa lógica, outros modelos concorrentes que emergiram com o intuito de preencher essa lacuna, replicaram em contextos culturais distintos, por exemplo, Lima et al. (2014), outros, em grande parte, incorporaram outros fatores exógenos, como, por exemplo, a educação e formação para o empreendedorismo (Peterman e Kennedy, 2003; Liñán et al., 2011). Em síntese, esses modelos concorrentes em grande parte, têm elementos fundamentais semelhantes e integrados em que todos se concentram na teoria de Shapero, de Ajzen e no conceito de autoeficácia de Bandura.

\subsection{Modelo Explicativo dos Antecedentes da Intenção Empreendedora - MAIE.}

Tomando como base os modelos apresentados e o arcabouço teórico revisado, foi proposto um modelo para tentar explicar as relações causais entre fatores antecedentes da intenção empreendedora junto a universitários, tais como a percepção da educação para o empreendedorismo, a percepção da autoeficácia empreendedora e a percepção da atratividade. No Modelo Explicativo dos Antecedentes da Intenção Empreendedora (MAIE), essas variáveis assumem a condição de preditoras da intenção empreendedora. O modelo agrega e, ao mesmo tempo, explica qual ou quais dessas variáveis são preponderantes na determinação da intenção empreendedora e, simultaneamente, as relações causais ou de associação entre as variáveis latentes. A figura 1 ilustra, graficamente, a proposta de modelo de intencionalidade testada.

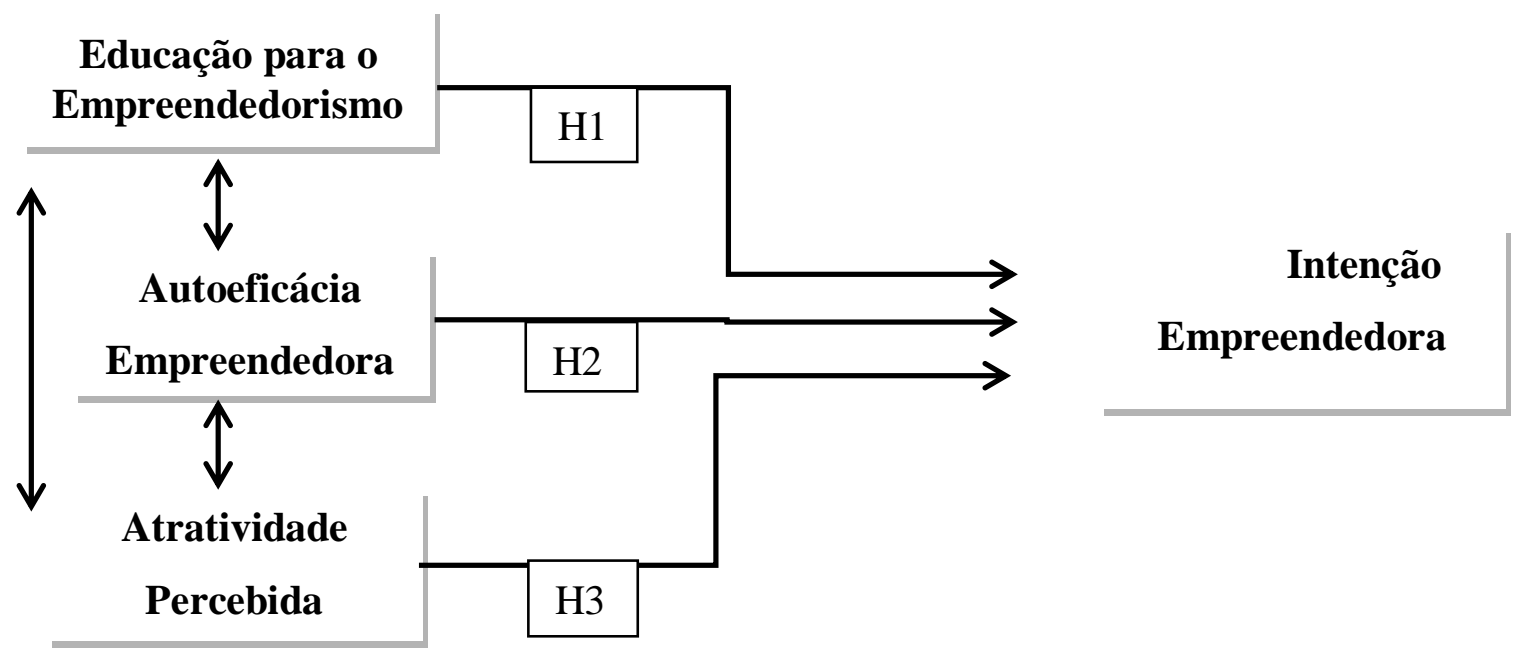

Figura 1 Modelo dos Antecedentes da Intenção Empreendedora - MAIE. O modelo inclui um caminho direto de variáveis exógenas e endógenas para explicar a intenção empreendedora e as relações entre as variáveis independentes.

Fonte: Elaboração própria. 
O estudo, ainda, baseia-se na visão de Krueger (2005) que coloca o comportamento empreendedor como voluntário, conduzido por mecanismos cognitivos. Em consonância com essa visão, o ponto de partida de ações empreendedoras é a formação da intenção empreendedora (Shapero \& Sokol, 1982; Ajzen, 1991).

A seguir, com maiores detalhes, as variáveis que compõem MAIE juntamente com as suas respectivas hipóteses.

\subsubsection{Educação para o Empreendedorismo - EE}

O papel da Educação para o Empreendedorismo (EE) tem sido compreendido como um dos principais instrumentos para aumentar as atitudes empreendedoras de pessoas. Dessa forma, iniciativas educacionais têm sido consideradas como altamente promissoras para aumentar a oferta de potenciais empresários. Para os fins deste trabalho, será adotada uma linha conceitual que considera a EE como instrumento pedagógico focado nos aspectos cognitivos e comportamentais dos indivíduos direcionados para o desenvolvimento socioeconômico e a criação de novos negócios.

Acerca dos efeitos da EE sobre a formação da intenção empreendedora, muito já foi feito. No entanto, ainda, persistem algumas contradições, principalmente, nas diferentes maneiras de medir o impacto dessa modalidade de ensino. Isso pode ser atribuído, segundo Venesaar et al. (2011), às dificuldades encontradas para avaliar programas de ensino do empreendedorismo. Para os autores, essa é uma questão complexa, quando não se tem a clareza suficiente sobre o que está medindo, o que, muitas vezes leva a escolhas de indicadores e procedimentos inadequados e insuficientes.

Outros estudos propuseram uma ligação positiva entre os impactos da EE e a intenção empreendedora (Peterman e Kennedy, 2003; Souitaris et al., 2007). As oportunidades de aprendizagem empreendedora, na visão de Patermen e Kennedy (2003), são susceptíveis de serem adaptadas para fornecerem resultados positivos para os indivíduos a entenderem o empreendedorismo e suas próprias circunstâncias.

Essas circunstâncias nos levaram à suposição de que a EE pode ter um papel mais importante para explicar a intenção empreendedora entre os universitários brasileiros. A fim de avaliar se essas construções existentes na literatura pertinente de modelos de intenções se encaixam com o MAIE, propomos a seguinte hipótese:

\section{H1: Educação para o Empreendedorismo está associada positivamente com a} intenção empreendedora dos universitários.

\subsubsection{Autoeficácia Empreendedora - AE}

A percepção de ter as habilidades necessárias para iniciar um novo negócio foi um dos temas relevantes na literatura, particularmente, no domínio do empreendedorismo. Essa percepção na visão de DE Clercq e Arenius (2006) é um fator crucial no processo empreendedor e fornece suporte para o argumento da autoeficácia, afirmando que os indivíduos são mais inclinados a exercerem as atividades empresariais se eles acreditam possuir as competências necessárias para empreender com sucesso essas atividades.

O conceito de controle comportamental percebido utilizado por Ajzen (1991) como a percepção da facilidade ou da dificuldade no cumprimento de comportamentos específicos,
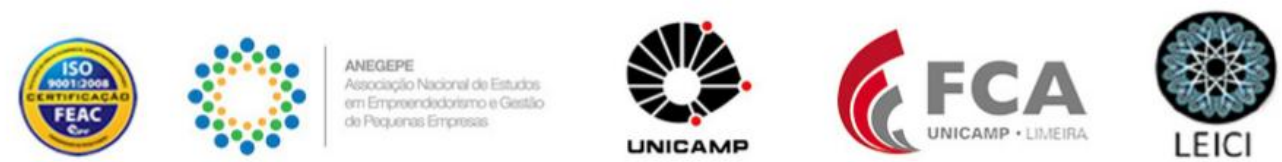
levando-se em conta experiências passadas, deficiências e obstáculos, por exemplo, tornar-se um empreendedor, está diretamente relacionado à noção que a pessoa tem de sua capacidade $\mathrm{e}$ do seu grau de controle sobre seu comportamento para agir. Essa definição do controle comportamental percebido concebida por Ajzen (1991) tem o mesmo significado da definição de autoeficácia apresentada anteriormente por Bandura: "is concerned with judgments of how well one can execute courses of action required to deal with prospective situations" (Bandura, 1982, p.122). Para os fins deste trabalho, foi adotado o termo autoeficácia empreendedora, uma vez que, possui o mesmo significado e sentido, tal como apresentado por Ajzen (1991) e Bandura (1982). Outros estudos, como, por exemplo, Sánchez (2011); Zhao et al. (2005) e Liñán et al. (2011) demonstraram com sucesso o poder preditivo da percepção de autoeficácia na formação da intenção empreendedora.

A inserção da percepção da autoeficácia empreendedora no modelo como um determinante na formação da intenção empreendedora, parece viável para mensurar o impacto diretamente sobre a intenção e, ao mesmo tempo, as relações com as outras variáveis do modelo. Com esses argumentos, foi formulada a segunda hipótese:

H2: A autoeficácia empreendedora dos universitários está associada positivamente com a intenção empreendedora.

\subsubsection{Atratividade Percebida - AP}

De um modo geral, as pessoas formam crenças sobre um objeto, associando-o com certos atributos, ou seja, com outros objetos, características ou eventos (Ajzen, 1991). As crenças comportamentais refletem uma atitude favorável ou desfavorável e exercem um papel relevante na avaliação do sentido que a pessoa tem do comportamento. Como os atributos vinculados ao comportamento já foram avaliados positiva ou negativamente, automática e simultaneamente, segundo Krueger et al. (2000), as pessoas adquirem uma atitude em relação a esse comportamento. Quanto mais positiva for a avaliação do indivíduo relativamente a um determinado comportamento, maior poderá ser a intenção demonstrada face à sua consumação.

Na Teoria do Evento Empresarial de Shapero e Sokol (1982) essas atitudes em direção ao comportamento, foram tratadas, especificamente, no contexto empresarial e foram denominadas de "conveniência percebida", numa tradução livre, referindo-se ao grau de atratividade pessoal para iniciar um negócio. No presente estudo, o termo cunhado por Ajzen (1991) e Shapero e Sokol (1982) de "Perceived Behavioral Control" e "Perceptions of Feasibility", respectivamente, semanticamente será tratada de "Atratividade Percebida" do comportamento, cuja definição, aqui entendida como o grau de especificidade do uso de atitudes em direção ao empreendedorismo.

Desse modo, foi estabelecida a terceira hipótese:

H3: Atratividade Percebida dos universitários está positivamente relacionada com a intenção empreendedora.

\subsubsection{Intenção Empreendedora - IE}

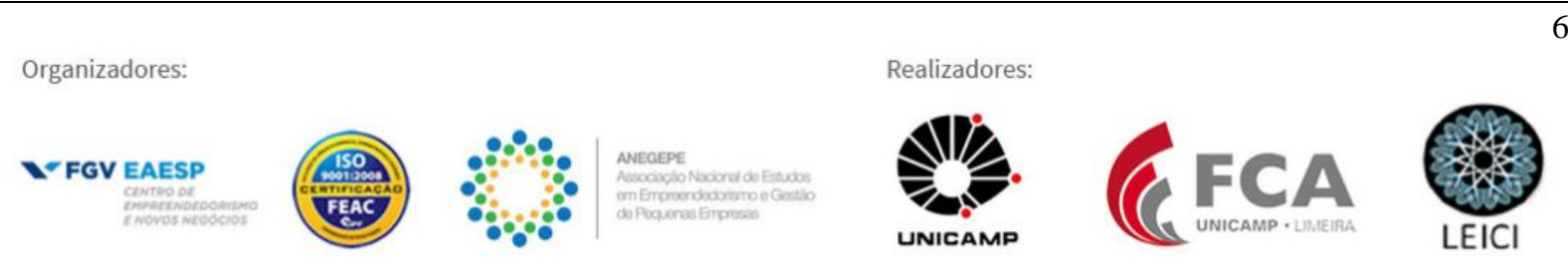


A intenção pessoal direcionada para comportamento empreendedor é o fator central na maioria dos modelos teóricos revisados. Os estudos sobre fatores que antecedem à sua formação assumem uma relevância especial para ser capaz de entender o processo de criação de empresas. A Intenção Empreendedora (IE) está mais propensa a desenvolver-se se em uma pessoa: i) se sente capaz de realizar com sucesso tarefas ou atividades empresariais (autoeficácia empreendedora); ii) se experiências de aprendizagem anteriores antecipam resultados positivos da atividade empresarial; e iii) se tem elevado interesse pessoal ou aspiração em direção ao empreendedorismo. De forma abrangente, o estudo da IE fornece uma maneira de fazer avançar a pesquisa sobre o empreendedorismo em contextos específicos.

Para Walter e Dohse (2012), estudar as intenções, especificamente, as empreendedoras, em princípio, tem duas vantagens; a primeira é ser considerada a melhor preditora do comportamento empreendedor e a segunda por refletir, diretamente, as influências de níveis mais elevados sem serem distorcidas por possíveis vieses de sobrevivência, ou o risco de identificar consequências em vez de determinantes do empreendedorismo. As relações de dependência da IE com outras variáveis consideradas independentes já foram testadas em várias situações, como, por exemplo, os estudos do efeito de programas e cursos de empreendedorismo sobre as competências (Sanchez, 2011).

\section{MÉTODO}

Para este estudo foi adotado uma abordagem quantitativa apoiada num survey longitudinal de natureza descritiva ao descrever características de determinada população - a intenção empreendedora e explicativa ao estabelecer relações entre variáveis numa perspectiva longitudinal. Foi selecionada, aleatoriamente, uma amostra de esses estudantes para a Análise Fatorial Exploratória (AFE) e para a Análise Fatorial Confirmatória (AFC) com recurso à modelagem de Equações Estruturais.

\subsection{Amostra de interesse (Participantes)}

Comumente, as amostras constituídas de estudantes universitários são consideradas adequadas para examinar a intenção empreendedora uma vez que os universitários se encontram em uma situação de escolha imediata de carreira (Krueger et al., 2000). Considerando que as variáveis utilizadas nesta investigação não eram específicas para os estudantes de um determinado curso, portanto, aplicáveis a outros grupos de estudantes de áreas de conhecimentos diferentes que, também, possam oferecer intenções e ideias na direção de algum tipo de negócio.

Os questionários foram distribuídos para aqueles estudantes matriculados em uma unidade curricular direcionada para o empreendedorismo. Quase todos os itens do questionário foram construídos como escalas de cinco pontos e distribuídos em quatro seções de variáveis, com exceção da variável IE, constituída por um bloco com duas questões: uma questão dictômica e outra com quatro itens sobre a IE dos estudantes. Os questionários foram aplicados em dois momentos distintos: no início do semestre acadêmico (T1) no ano de 2014 - aplicado no primeiro dia de aula, ou no máximo na segunda semana, para todos os presentes e ao final do mesmo semestre (T2), no ano de 2015. Ao final, em ambos os períodos, foi possível obter 558 questionários respondidos e validados.
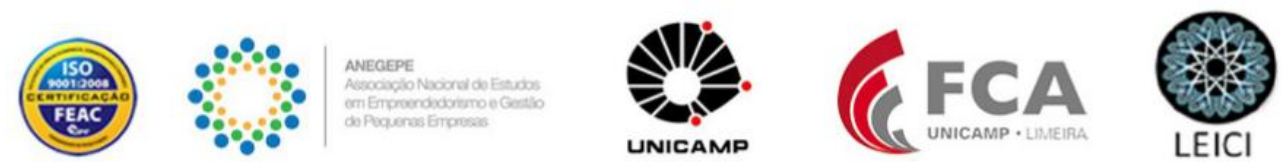


\subsection{Tratamento estatístico dos dados}

Dada as interrelações entre as variáveis independentes além, claro das relações diretas com a variável dependente, o estudo apoiou-se na técnica de Modelagem de Equações Estruturais (Structural Equations Modeling - Análise de Equações Estruturais - AEE) por incluir variáveis manifestas e variáveis latentes num mesmo quadro teórico. Dessa forma, permite a análise de um conjunto de relações entre uma ou mais variáveis independentes e dependentes, contínuas ou discretas. Diferentemente dos modelos clássicos, que são inapropriados para tratar com a complexidade de modelos teóricos quando envolvem múltiplas variáveis manifestas e latentes, efeitos de mediação, entre outros, a AEE testa o ajustamento global do modelo a partir da assunção por parte do investigador de uma relação causal entre variáveis.

Antes da análise definitiva dos dados, foram realizados alguns testes preliminares de dados para cada uma das variáveis em estudo, com o objetivo de verificar as condições necessárias para a aplicação de uma Análise Fatorial (AF). Foram realizados testes estatísticos para verificação da assimetria e da curtose. A análise estatística do modelo foi realizada com o software SPSS - Statistical Package for Social Sciences (versão 21.0) e o AMOS - Analysis of Moment Structures (versão 20.0.0), usando o método da máxima verossimilhança aplicado aos itens originais.

\section{ANÁLISES E DISCUSSÃO DOS RESULTADOS}

As evidências encontradas foram comparadas com os contributos teóricos na área para verificar se eles eram significativos e se correspondiam a avanços a partir das descobertas do presente estudo. Com o intuito de oferecer maior clareza e objetividade na comunicação dos resultados obtidos, os mesmos serão apresentados de maneira individualizada nos dois horizontes temporais.

\subsection{Os resultados em $\mathrm{T} 1$}

Os estudantes autodeclararam possuir elevado nível de IE $(72,6 \%)$ distribuída por diversas características sociodemográficas: i) Gênero: os homens $(43.3 \%)$ apresentaram níveis mais elevados de IE do que as mulheres $(40,6 \%)$;ii) Faixa etária: maior concentração entre os 20 e 26 anos de idade.

Os índices de qualidade de ajustamento do modelo revelaram uma adequação "muito boa" da estrutura à amostra do estudo (ver figura 2). Todos os índices apresentaram pesos fatoriais elevados $(\lambda \geq 0.5)$. 
Modelo dos antecedentes da Intenção empreendedora

--1a. Etapa: Modelo de Medida---

$\times 2(141)=301,932 ; p=, 000 ; X 2 / d f=2,141$

$\mathrm{CFI}=, 959 ; \mathrm{GFI}=, 911$,

RMSEA = ,060; $P($ rmsea $<0.05)=, 035 ; M E C V I=1,299$

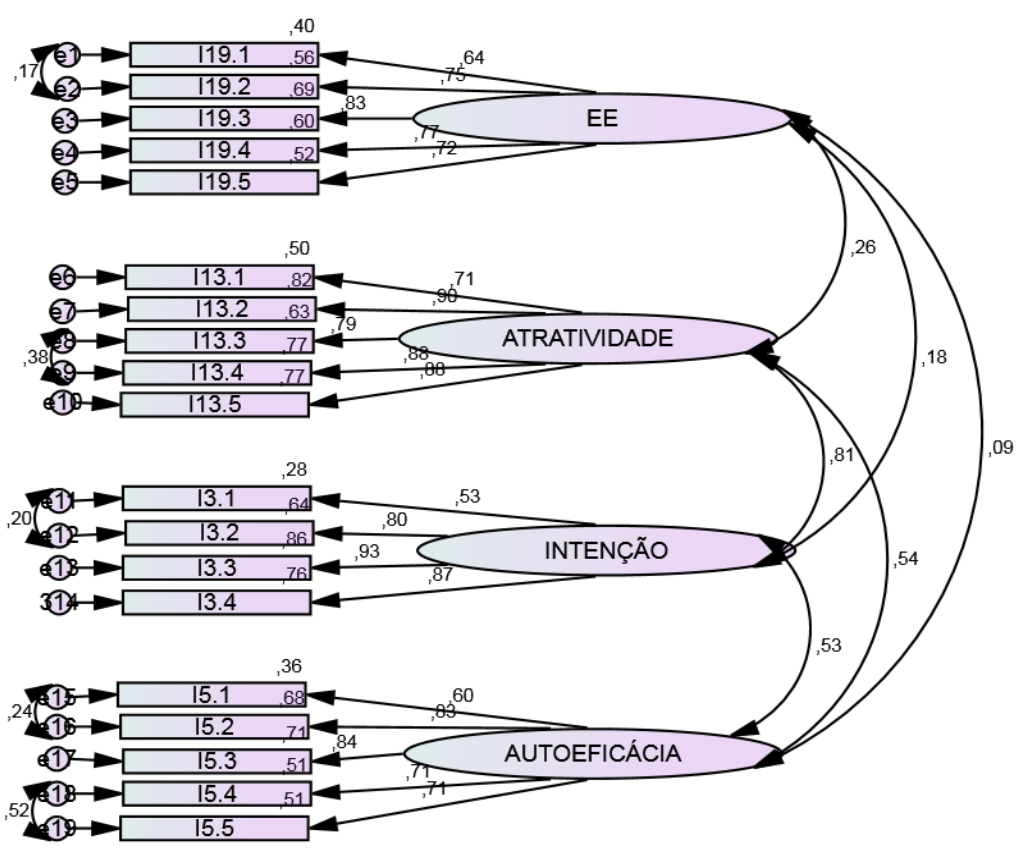

Figura 2. Análise Fatorial Confirmatória do modelo após modificação de acordo com os índices de modificação.

Fonte: Output do software SPSS - (versão 21.0) e o AMOS (versão 20.0.0).

Após a extração a variância total explicada das componentes principais apresentou valores elevados; juntos, os fatores explicaram $64.26 \%$ da variância total. As correlações entre a variável EE e as variáveis $\mathrm{AE}(0,089)$, IE $(0,180)$ e $\mathrm{AP}(0,261)$ foram as que apresentaram os menores escores no tempo T1. As correlações mais elevadas foram registradas entre a variável $\mathrm{AP}$ e as variáveis IE e AE, 0,809 e 0,544, respectivamente. A correlação entre a $\mathrm{AE}$ e IE foi de 0,534. Todos os fatores apresentaram boa fiabilidade compósita: $\mathrm{EE}=0.877$; $\mathrm{AP}=$ 0.941 e $\mathrm{AE}=0.890$ e a variância extraída média $(\mathrm{VEM})$ por cada fator foi $\mathrm{EE}=0.591 ; \mathrm{AP}=$ 0.642 e AE $=0.626$. Segundo Marôco (2010, p.176), considera-se validade convergente adequada para VEM $>0,5$. Neste estudo, todos os fatores apresentaram validade convergente adequada.

A segunda etapa (two-step), a avaliação do modelo causal, foi feita, tal como na primeira etapa, atendendo aos mesmos índices de qualidade de ajustamento. O modelo causal apresentou os mesmos índices de qualidade de ajustamento do modelo de medida, indicando que o ajustamento da estrutura à amostra do estudo é "muito bom" (ver figura 3). A figura, ainda, apresenta os valores dos pesos estandardizados e a fiabilidade individual de cada um 
dos itens no modelo. O MAIE ajustado explica $67 \%$ da variabilidade dos fatores antecedentes relativas à IE.

Modelo dos antecedentes da Intenção empreendedora

---2a. Etapa: Modelo causal ---

$X 2(141)=301,932 ; p=, 000 ; X 2141=2,141$

$\mathrm{CFI}=, 959 ; \mathrm{GFI}=, 911$

RMSEA $=, 060 ; \mathrm{P}($ rmsea $<0.05)=, 035 ; \mathrm{MECVI}=1,299$

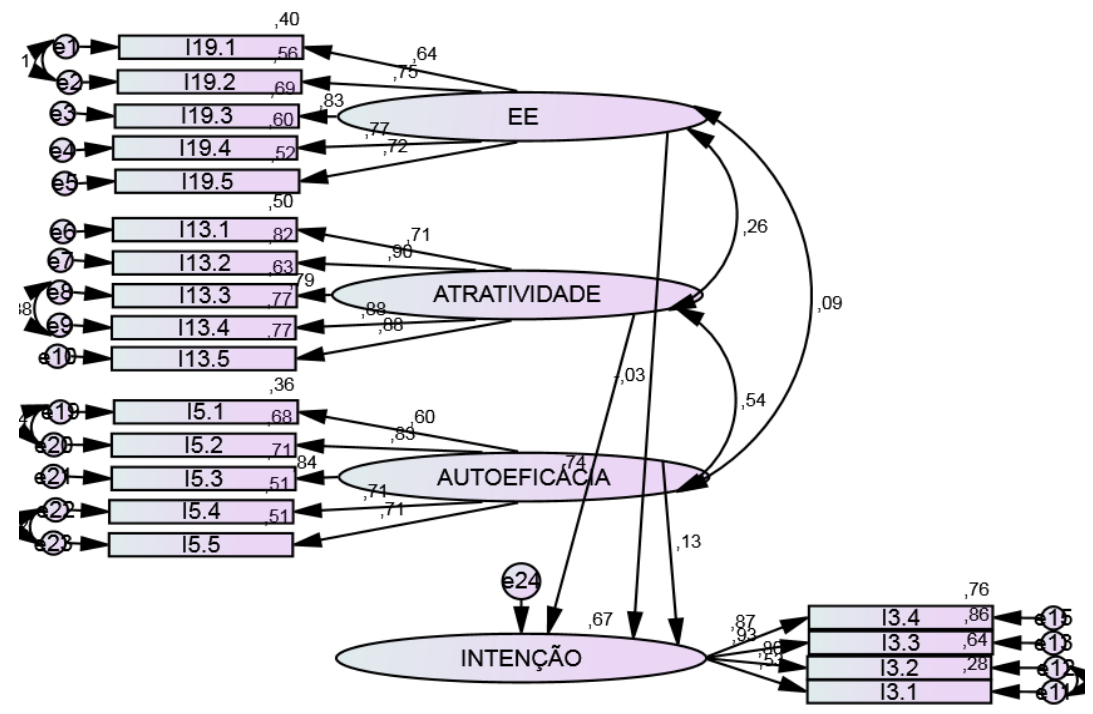

Figura 3 - Modelo causal dos antecedentes da Intenção empreendedora em T1 - Diagrama com estimativas estandardizadas das trajetórias e dos $\mathrm{R}^{2}$ dos itens e do fator "Intenção".

Fonte: Output do software SPSS - (versão 21.0) e o AMOS (versão 20.0.0)

Quanto à hipótese $H 1, a$ análise da trajetória revelou que o peso de regressão para EE na predição da INTENÇÃO (trajetória "EE $\rightarrow$ IE") não foi estatisticamente significativo no nível de $0,05\left(B_{E E . I n t e n c ̧ a ̃ o}=-, 044 ; S E=, 073 ; \beta_{E E \text {. Intenção }}=-, 03\right.$ (ver Figura 3 ) e; $p=, 550 . \mathrm{O}$ peso fatorial negativo (-,03), a priori, frustra as expectativas. A negatividade revela que o efeito, que tinha sido hipotetizado, não se verificou no T1. Dessa forma, a $H 1$ apresentada não foi suportada pelo modelo. Estes achados corroboram os estudos realizados por Lima et al. (2014), a partir dos dados da versão brasileira de 2011 do Global University Entrepreneurial Spirit Students' Survey (GUESSS) obtidos junto a 25.751 estudantes brasileiros de 37 faculdades e universidades. Da mesma forma, o efeito negativo significativo sobre a percepção da $\mathrm{AE}$.

Quanto à hipótese $H 2$ a trajetória "AP $\rightarrow$ IE" foi estatisticamente significativa no nível de 0,05 e apresentou o maior peso fatorial para o nível de 0,05 ( $B_{E E . I E}=, 776 ; \mathrm{SE}=, 063$; 
$\beta_{E E . I E}=, 74$; (ver figura 3 ) e $p=, 000 . \mathrm{O}$ peso fatorial positivo revela que o efeito que tinha sido hipotetizado se verificou no $\mathrm{T} 1$.

Quanto à hipótese $H 3$, a trajetória "AE $\rightarrow$ IE" foi significativamente diferente de zero no nível de 0,05 (bi-caudal) e apresentou peso fatorial para o nível de 0,05 ( $B_{A E . I E}=, 182 ; \mathrm{SE}=$ , $073 ; \beta_{A E . I E}=, 131 ;$ (ver Figura 3 ) e $p=, 013$. O efeito total estandardizado da AE sobre a IE $(, 115)$ e o peso fatorial positivo revelam que o efeito que tinha sido hipotetizado se verificou no T1 embora não seja estatisticamente significativo $(p=, 13)$. No entanto, a $H 3$ trata da relação de positividade entre a $\mathrm{AE}$ e a IE.

\subsection{Resultados em T2}

Após a extração das componentes principais, todas as variáveis apresentaram valores elevados e, juntas, explicaram 77,084\% da variância total, superior à variância total explicada no $\mathrm{T} 1 \mathrm{de} 64,26 \%$.
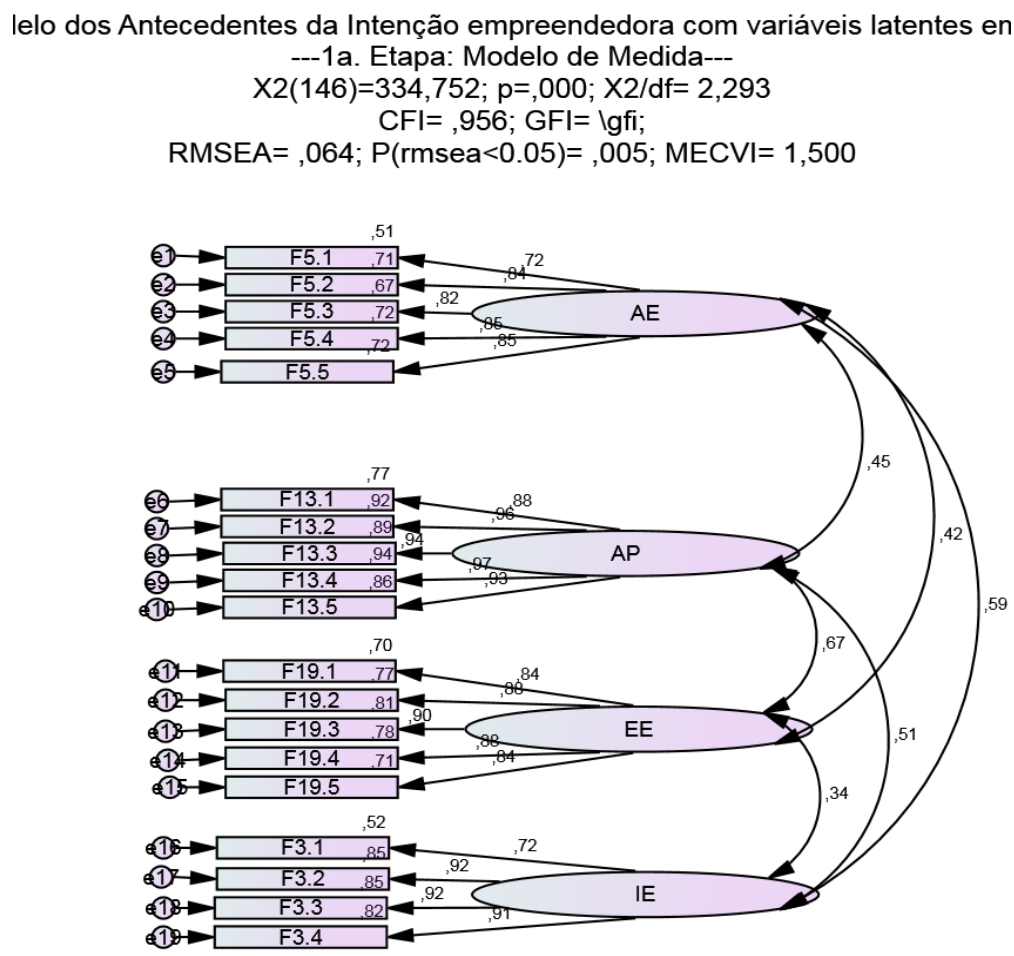

Figura 4. Análise Fatorial Confirmatória do modelo dos antecedentes da intenção empreendedora de acordo com os índices de modificação e considerações teóricas após modificação do modelo. Fonte: Output do software SPSS - (versão 21.0) e o AMOS (versão 20.0.0)

A taxa autorrelatada encontrada da IE dos estudantes no T2 $(67,6 \%)$ foi inferior às encontradas no T1 (72.9\%). A IE, quando cruzada com o gênero, sofreu alterações pós-curso. A taxa de "sim" para os homens no T1 de $43.3 \%$ subiu para $63.6 \%$ no T2, enquanto a taxa das mulheres caiu de $40.2 \%$ para $36.4 \%$. 
Quanto à validade fatorial, todos os pesos fatoriais estandardizados foram elevados $(\lambda \geq 0.5)$. A figura 4 apresenta os índices de qualidade de ajustamento da estrutura à amostra do estudo, que foi classificada como uma adequação "muito boa". As correlações entre variáveis apresentaram bons escores (ver Figura 4). As correlações com escores mais elevados foram verificadas entre as variáveis EE e AP $(0.67)$, IE e AE, $(0,59)$ e AP e IE $(0.51)$ e as correlações com menores pesos foram EE e IE (0.34) e EE e AE (0.42). Todos os fatores apresentaram boa fiabilidade compósita: $\mathrm{EE}=0,939 ; \mathrm{AP}=0,969$ e $\mathrm{AE}=0,937 \mathrm{e}$ a Variância Extraída Média (VEM), por cada fator foi $\mathrm{EE}=0,755$; $\mathrm{AP}=0,778624$ e $\mathrm{AE}=0,752$. Todos os fatores apresentaram validade convergente adequada.

$\mathrm{Na}$ segunda etapa (two-step) da análise e da avaliação do modelo causal, foi confirmado que o MAIE apresenta os mesmos índices de qualidade de ajustamento do modelo de medida, indicando que o ajustamento da estrutura à amostra do estudo é "muito bom" (ver Figura 5).

Modelo dos Antecedentes da intenção empreendedora em T2

---2a. Etapa: Modelo Causal---

$X 2(146)=334,752 ; p=, 000 ; X 2 / d f=2,293$

$\mathrm{CFI}=, 956 ; \mathrm{GFI}=\mathrm{Igfi} ;$

$;$ RMSEA $=, 064 ; \mathrm{P}($ rmsea $<0.05)=, 005 ; \mathrm{MECVI}=1,500$

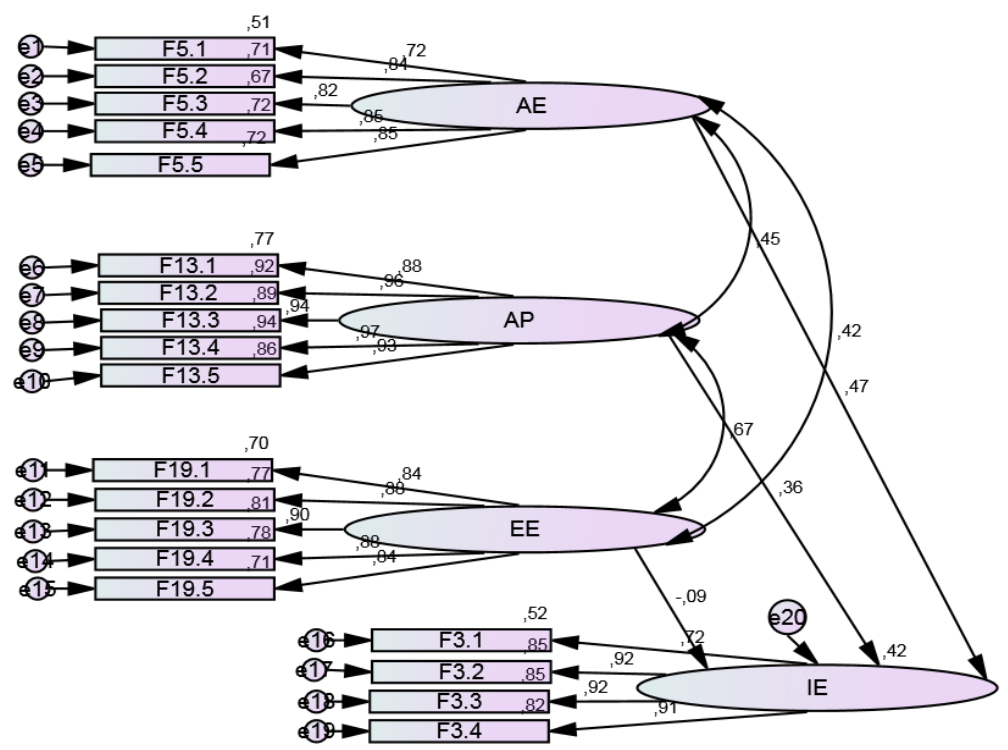

Figura 5 - Modelo causal de antecedentes da IE.

Estimativas estandardizadas das trajetórias e dos $\mathrm{R}^{2}$ dos itens e do fator "IE".

Fonte: Output do software SPSS - (versão 21.0) e o AMOS (versão 20.0.0)

O MAIE ajustado explica $42 \%$ da variabilidade dos fatores antecedentes relativos à intenção empreendedora.

Quanto à hipótese $H 1$, o peso de regressão para EE na predição da IE (trajetória "EE $\rightarrow$ IE") não é estatisticamente significativo no nível de $0,05\left(B_{E E . I E}=-, 126 ; S E=, 109 ; \beta_{E E . I E}=\right.$ ,$- 09 ; p=, 248$ (ver figura 5). Esses indicadores, quando comparados com os encontrados no 
T1, são menos estatisticamente significativos. O efeito total padronizado da variável EE sobre a IE é -,09. O peso fatorial negativo frustra, ainda mais, as expectativas no T2. A negatividade revela que o efeito que tinha sido hipotetizado não se verificou no T2, mesmo que os estudantes tivessem vivenciado uma experiência de ensino formal com uma disciplina relacionada ao empreendedorismo durante sua graduação. A percepção da EE não influenciou positivamente a IE. Oosterbeek et al. (2010) encontraram resultados semelhantes; o efeito da autoavaliação dos estudantes, após participarem de um programa de EE, sobre as competências empresariais era insignificante e, sobre a intenção empreendedora, era negativo.

A H1 testada com os dados do T2 não foi suportada como se esperava e predito com base na literatura revisada, que considerava a possibilidade de uma relação bidirecional entre esses constructos. Os resultados podem, eventualmente, ser relacionados ao fato de que os alunos tenham obtido perspectivas mais realistas sobre o que é preciso para ser um empreendedor.

Quanto à $\mathrm{H} 2$, a trajetória $\mathrm{AP}$ na predição da IE (“AP $\rightarrow$ IE”) é estatisticamente significativa no nível de 0,05 ( $B_{E E . I E}=, 348 ; S E=, 079 ; \beta_{E E . I E}=, 670 ; p=, 000$. Diferentemente dos achados no T1, quando essa variável apresentou o maior peso fatorial entre as variáveis estudadas, no T2, o peso fatorial revelado foi menor do que o peso apresentado pela percepção da AE. O peso fatorial positivo revela que o efeito que tinha sido hipotetizado se verificou no T2. No entanto, essa percepção, pós-participação em curso de empreendedorismo, ter sido significativamente relacionada à IE, deve-se ressaltar que esse efeito direto sobre a IE foi inferior ao registrado no primeiro período, sem a intervenção da unidade curricular.

Sob a perspectiva do referencial teórico revisado, particularmente, a TPB de Ajzen (1991) e a Teoria do Evento Empresarial de Shapero e Sokol (1982) e os trabalhos empíricos de Liñán et al. (2011) e Zahao et al (2005), os resultados para a $H 2$ corroboram com as crenças comportamentais como preconizadas por esses referidos estudos. O papel relevante da AP no desenvolvimento da intenção, que gera as atitudes em direção ao comportamento, comportou-se como um extraordinário preditor da intenção empreendedora.

Quanto à $H 3$ a trajetória $\mathrm{AE}$ na predição da $\mathrm{IE}$ (trajetória "AE $\rightarrow$ IE") é estatisticamente significativa para o nível 0,05. $\left(B_{A E . I E}=, 690 ; \mathrm{SE}=, 105 ; \beta_{A E . I E}=, 470\right.$; (ver Figura 5) e $p=, 000$. O efeito total estandardizado da AE sobre a IE e o peso fatorial positivo revelam que o efeito que tinha sido hipotetizado se verificou no T2. O efeito direto total (estandardizado) nesse período foi superior ao escore encontrado no período anterior. Enquanto no T1, o efeito direto foi de $B_{A E I E}=, 131$ no T2 foi $B_{A E . I E}=, 690$. Esse desempenho da AE como preditora da IE, hipotetizado, confirma o seu posicionamento como fator relevante no processo empreendedor, confirmando a relação direta entre indivíduos propensos a exercer atividades empresariais e suas crenças em possuir as competências necessárias para empreender com sucesso essas atividades.

Os resultados desta investigação para o T2 corroboram com as explicações teóricas de Shapero e Sokol (1982), Bandura (1986) e Ajzen (1991), permitindo-nos reforçar que a confiança na capacidade pessoal de agir empreendedoramente é fator preponderante, que deverá ser incluído nas discussões curriculares dos sistemas educativos e dos formuladores de políticas públicas de desenvolvimento.
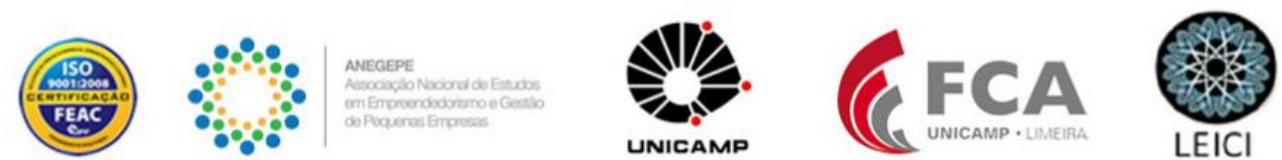


\section{CONSIDERAÇÕES FINAIS}

As descobertas fornecem algumas importantes implicações teóricas e práticas. Entre elas, a tentativa de estabelecer uma série de ponderações sobre a relação entre a oferta da orientação pedagógica para os cursos universitários com o objetivo de promover atitudes e intenções empreendedoras dos estudantes e fornecer um caminho alternativo para pesquisadores no campo de estudos de educação e de empreendedorismo.

Com base nos resultados é razoável afirmar que é necessário fazer muito mais do que simplesmente criar e implantar disciplinas, cursos ou programas de empreendedorismo nas IES. É essencial que, pedagogicamente, se faça, inicialmente, uma opção metodológica consciente dos objetivos curriculares pretendidos. Se o objetivo for a transmissão de conhecimentos e informações, o que se faz na atualidade pode ser considerado razoável para ensinar empreendedorismo; no entanto, se o objetivo for o desenvolvimento da intenção empreendedora e a promoção do empreendedorismo com a criação de novos negócios, pode, razoavelmente, defender a inclusão da autoeficácia empreendedora e do desenvolvimento da atratividade nas matrizes e práticas curriculares dos cursos de graduação e pós-graduação ofertados pelas IES, como fatores fundamentais para a formação da intenção empreendedora, uma vez que, entre as variáveis analisadas, essas variáveis foram as que mais explicaram a intenção empreendedora.

Os resultados encontrados, tanto no T1 como no T2, ajustam-se às teorias em estudo, fornecendo suporte empírico para os argumentos de Bandura (1986) e Ajzen (1991), quanto aos antecedentes da formação da intenção empreendedora e para os estudos de Shapero e Sokol (1982), Zahao et al. (2005) e Liñán et al. (2011), especificamente, sobre a relação positiva entre a variável autoeficácia empreendedora $\mathrm{e}$ as intenções individuais de empreender.

Os motivos e as aspirações para empreender podem ocorrer em tempos e contextos diferentes, que pressionam os sistemas de ensino-aprendizagem a superarem os desafios ao criarem ambientes de aprendizagem próprios para atender às diferentes demandas vindas de diferentes culturas. Por isso, essa é uma abordagem interessante na atualidade, em função de vários aspectos que levam em conta o atual debate sobre a questão do papel das IES para alavancar o desenvolvimento econômico e social das nações, incluindo a EE no centro estratégico das decisões.

É verdadeira a elevada intencionalidade de empreender dos estudantes de graduação no Brasil tal como a de outros estudantes em outros paises. No entanto, os impactos propagados pela literatura e as hipóteses aqui levantadas sobre o impacto do ensino do emporeendedorismo sobre a intençaoa empreendedora não foram suportados pelo MAIE em nenhum dos dois períodos analisados, chegando a ser ainda menos impactante no período T2, justamente no pós-curso. Contudo, mesmo que as intenções empreendedoras diminuam como consequência da formação em empreendedorismo como já argumentado por Oosterbeek et al. (2010), essa relação de negatividade pode ser socialmente avaliada como positiva, considerando uma nova tomada de consciência realista do processo empreendedor.

Os resultados deste trabalho reforçam e comungam de que a ineficácia dos cursos e programas de empreendedorismo, quando desprovidos de uma proposta curricular adequada ao desenvolvimento da intenção de empreender podem, como foi aqui, gerar impactos negativos. A EE, per si, não impacta diretamente, como se esperava, a intencionalidade

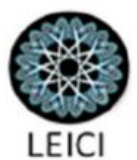


individual dos estudantes, mas que, indiretamente, poderá alterar positivamente as variáveis cognitivas, especialmente a autoeficácia empreendedora no sentido da formação da IE.

\subsection{Limitações e implicações futuras}

Esta abordagem, contudo, tem suas limitações. Primeiro, a distribuição da amostra. As dimensões continentais e a variedade de contextos culturais do Brasil exigem um volume maior de recursos humanos e financeiros, que, muitas vezes, não estão disponíveis. Diante dessa limitação, a amostra ficou concentrada numa única região brasileira, o que pode ser um fator limitante para a aplicabilidade de nossos resultados a outros grupos.

Outros grupos poderiam ser estudados, como alunos do ensino médio e aqueles que levam a cabo atividades empresariais nas incubadoras, por exemplo. Sendo assim, recomenda-se que estudos futuros sejam baseados em um conjunto maior de dados de forma que a intenção empreendedora dos estudantes possa ser comparada, antes e depois de participação em um curso/programa de empreendedorismo. O uso exclusivo de medidas de autorrelato a partir de uma única base de informação, são, naturalmente, vulneráveis a uma série de influências e preconceitos. Nesse sentido, seria enriquecedor a replicação do estudo com outras variáveis, tais como a metodologia adotada em sala de aula e o grau de aprendizagem formal para avaliar a real aprendizagem dos alunos.

Os resultados descritos neste estudo oferecem implicações diretas para um conjunto de "consumidores" da educação para o empreendedorismo e do empreendedorismo. Entre eles, os praticantes e aspirantes a empresários, educadores de empreendedorismo, graduandos, formuladores e gestores de políticas públicas e outros responsáveis pelo desenvolvimento e apoio aos ecossistemas empresariais a partir de vários aspectos, entre eles: i) corroborar opinião de que o processo empreendedor inicia-se com a intenção de empreender. Nesse caso, fomentar e alimentar a intenção, presumidamente, será um fator crítico de sucesso do processo de desenvolvimento do empreendedorismo, por meio do ensino nas IES; ii) a reforma educacional dos programas/cursos de empreendedorismo, particularmente, de graduação, é imperativa no sentido de que possa direcionar seus esforços e orientá-los para modelos pedagógicos com foco no desenvolvimento da autoeficácia empreendedora e da percepção da atratividade como os antecedentes mais influentes e de maior poder explicativo na predição da intenção empreendedora.

\section{REFERÊNCIAS}

Ajzen, L. (1991). The theory of planned behavior. Organizational Behavior and Human Decision Processes, 50, 179-211.

Bandura, A. (1986). The Social Foundations of Thought and Action. Englewood Cliffs: Prentice-Hall.

Baron, R. A., e Shane, S. A. (2007). Empreendedorismo: uma visão do processo. São Paulo: Thomson Learning.

DE Clercq, D. \& Arenius, P. (2006). The role of knowledge in business start-up activity. International Small Business Journal. 24:4 339-358.

Lima, E. et al. (2014). Educação Superior em Empreendedorismo e Intenções Empreendedoras dos Estudantes. Relatório do Estudo GUESSS Brasil 2013-2014. Grupo
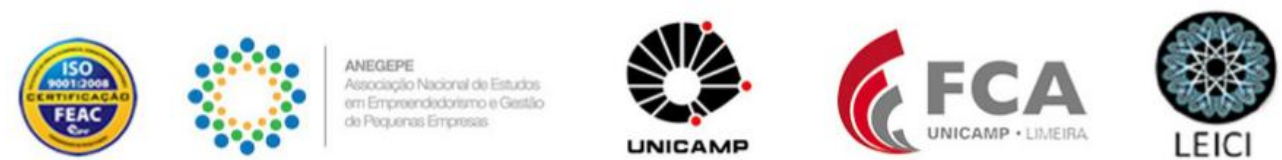
APOE - Grupo de Estudo sobre Administração de Pequenas Organizações e Empreendedorismo, PPGA-UNINOVE. Caderno de Pesquisa, São Paulo, n. 2014-03,

Liñán, F, Rodriguez-Cohard, J. C. Rueda-Cantuche, J. M. (2011). Factors affecting entrepreneurial intention levels: a role for education. International Entrepreneurship and Management Journal 7:2 195-218.

Krueger, N. F. (2005). Sustainable entrepreneurship: Broadening the definition of “opportunity". SSRN Accepted Paper Series, 7: Entrepreneurship in a Diverse World.

Krueger, N. F., Reilly, M. D. e Carsrud, A. L. (2000). Competing models of entrepreneurial intentions. Journal of Business Venturing, 15 (5-6), 411-432.

Marôco, J. (2010). Análise de Equações Estruturais. Pero Pinheiro: Report Number.

Medeiros, P. C., Loureiro, S. R., Linhares, M. B. M. \& Marturano, E. M. (2000). A Autoeficácia e os Aspectos Comportamentais de Crianças com Dificuldade de Aprendizagem. Psicologia: Reflexão e Crítica, 13(3), 327-336.

Oosterbeek, V., van Praag, M. \& Ijsselstein, A. (2010).The impact of entrepreneurship education on entrepreneurship skills and motivation. European Economic Review 54:3 442454.

Peterman, N. E. e Kennedy, J. (2003). Enterprise Education: Influencing Students' Perceptions of Entrepreneurship. Entrepreneurship Theory and Practice, 28: 129-144.

Raposo, M. L. B., e do Paço, A. M. F. A. (2011). Entrepreneurship education: relationship between education and entrepreneurial activity. Psicothema 23:3 453-457.

Sanchez, J. C. (2011). University training for entrepreneurial competencies: its impact on intention of venture creation. International Entrepreneurship and Management Journal 7:2 (2011) 239-254.

Shapero, A. e Sokol, L. (1982). The Social Dimensions of Entrepreneurship. Encyclopedia of Entrepreneurship, Vol., p. 72-90. Available at SSRN: http://ssrn.com/abstract=1497759.

Software SPSS - Statistical Package for Social Sciences (versão 21.0) e o AMOS - Analysis of Moment Structures

Souitaris, V., S. Zerbinati, e A. Al-Laham (2007): Do entrepreneurship programmes raise entrepreneurial intention of science and engineering students? The effect of learning, inspiration and resources. Journal of Business Venturing 22 (4):566-591.

Venesaar, U., Ling, H., Voolaid, K. (2011). Evaluation of the entrepreneurship education programme in university: a new approach. Amfiteatru Economic, 13:30 377-391

Ucbasaran, D., Westhead, P. (2008). Wright, m, opportunity identification and pursuit: does an entrepreneur's human capital matter? Small Business Economics 30:2 153-173.

Zahao, H., Seibert, S. E., e Hills, G. E. (2005). The mediating role of self-efficacy in the development of entrepreneurial intentions. Journal of Applied Psychology.90:6 - 1265-1272.

Walter, S. G. e Dohse, D. (2012). Why mode and regional context matter for entrepreneurship education. Entrepreneurship and Regional Development, 24:9-10 (2012) 807-835. 